\title{
Molecular properties and potential energy surfaces of the cyanides of the groups 1 and 11 metal atoms
}

\author{
Dong-ki Lee, Ivan S. Lim, and Yoon Sup Lee ${ }^{a)}$ \\ Department of Chemistry, Korea Advanced Institute of Science and Technology, 305-701 Daejeon, Korea \\ and School of Molecular Sciences (BK21), Korea Advanced Institute of Science and Technology, \\ 305-701 Daejeon, Korea \\ Denis Hagebaum-Reignier and Gwang-Hi Jeung ${ }^{b}$ \\ Chimie Théorique, Case 521 (CNRS, UMR 6517), Université de Provence, Campus de Saint-Jérôme, \\ 13397 Marseille Cedex 20, France
}

(Received 4 January 2007; accepted 22 May 2007; published online 29 June 2007)

\begin{abstract}
$A b$ initio calculations on the metal (groups 1 and 11) cyanide complexes show two stable configurations for the ground state geometry, a linear cyanide (MCN) and a triangular (MNC) form with an obtuse $\mathrm{M}-\mathrm{N}-\mathrm{C}$ angle. Lithium complex may exist in a linear isocyanide (MNC) form, but it cannot be differentiated from the triangular configuration because of the flatness of the potential energy surface connecting the two isomers. The metal atom and cyano radical are bonded through a strongly ionic configuration $\left(\mathrm{M}^{+} \mathrm{CN}^{-}\right)$in both geometrical forms. The $\mathrm{MNC}$ triangular form is a very floppy structure having one low frequency for the bending mode, whereas the $\mathrm{MCN}$ linear form is more rigid. The $\mathrm{CN}$ complexes of the alkali atoms have a triangular geometry as the lowest energy conformer, while the noble metal atoms prefer the linear cyanide one. The relative stability of the two isomers, dipole moments, and effective charges are reported in this paper. The essential aspects of the potential energy surfaces for the ground and the first excited states exhibiting a closely avoided crossing are also explained. (C) 2007 American Institute of Physics.
\end{abstract}

[DOI: $10.1063 / 1.2749504]$

\section{INTRODUCTION}

The relative stability between different conformers of cyanide complexes of a metal atom has been a subject to many scientific investigations by quantum mechanical calculations. ${ }^{1-6}$ There are the linear cyanide $(\mathrm{MCN})$, linear isocyanide (MNC), and the triangular (sometimes written as $\mathrm{M}[\mathrm{CN}])$ forms. They are characterized by a monocoordination (monohapto, $\eta^{1}$ according to the organometallic notation) for the linear two forms and a bicoordination (dihapto, $\eta^{2}$ ) for the triangular form. Historically, the first infrared absorption spectra of the triatomic cyanides of $\mathrm{Na}$ and $\mathrm{K}$ were observed by Leroi and Klemperer. ${ }^{7}$ They noted that the $\mathrm{C}-\mathrm{N}$ stretching frequency $\left(\nu_{3}\right)$ in $\mathrm{XCN}(\mathrm{X}=\mathrm{H}, \mathrm{Na}, \mathrm{K}, \mathrm{Cl}$, $\mathrm{Br}$, and I), in general, appeared rather insensitive to the nature of the $\mathrm{X}$ atom and reported the measured values of $2176 \pm 5$ and $2158 \pm 5 \mathrm{~cm}^{-1}$ for $\mathrm{NaCN}$ and $\mathrm{KCN}$, respectively, which assumed a linear cyanide configuration, in comparison with the free $\mathrm{CN}$ value ${ }^{8}$ of $2068.59 \mathrm{~cm}^{-1}$. However, they also observed low-frequency vibrations at $239 \pm 10$ and $207 \pm 20 \mathrm{~cm}^{-1}$ for $\mathrm{NaCN}$ and $\mathrm{KCN}$, respectively. These bands were presumably assigned to the bending mode $\left(\nu_{2}\right)$. More than a decade later Ismail et al. ${ }^{9}$ found linear geometries for the cyanides of $\mathrm{Li}, \mathrm{Na}$, and $\mathrm{K}$ atoms from isotopic substitutions and reported frequencies for the three modes of vibration from their matrix-isolation study. Their bending frequencies, however $\left(119,168\right.$, and $139 \mathrm{~cm}^{-1}$ for $\mathrm{LiCN}, \mathrm{NaCN}$, and

\footnotetext{
${ }^{\text {a)} E l e c t r o n i c ~ m a i l: ~ y o o n s u p l e e @ k a i s t . a c . k r ~}$

${ }^{b)}$ Electronic mail: jeung@up.univ-mrs.fr
}

$\mathrm{KCN}$, respectively), were much smaller than those reported earlier by Leroi and Klemperer. Later, van Vaals et al. ${ }^{10}$ and Törring et al. ${ }^{11}$ have reported the microwave absorption and molecular-beam electric-resonance rotational spectra of the gaseous $\mathrm{Li}, \mathrm{Na}$, and $\mathrm{K}$ cyanides. These studies suggested a nonlinear bent form (or a $T$ form) as the ground state geometry for the $\mathrm{Na}$ and $\mathrm{K}$ complexes while a linear isocyanide form was concluded to be most stable for the $\mathrm{Li}$ complex. The $\mathrm{M}-\mathrm{C}$ distance was slightly longer than the $\mathrm{M}-\mathrm{N}$ distance, while the $\mathrm{C}-\mathrm{N}$ distance showed a little variation from that of free cyanide $\left[r_{e}(\mathrm{C}-\mathrm{N})=1.170(4)\right.$ and 1.162(10) $\AA$ for $\mathrm{NaCN}$ and $\mathrm{KCN}$, respectively, in comparison with $1.1718(2) \AA$ for free cyanide, see Ref. 8]. To the best of our knowledge, no experimental or theoretical data were reported on $\mathrm{RbCN}$, CsCN, or FrCN.

For the light alkali metal cyanide complexes early $a b$ initio calculations showed that $\mathrm{LiCN}$ was most stable in the isocyanide configuration at the Hartree-Fock (HF) level ${ }^{24}$ with a small isomerization energy to the cyanide conformer $(8.8 \mathrm{kcal} / \mathrm{mol})$. The barrier height between the two conformers was calculated to be lower at the correlated level due mainly to the stabilization of the cyanide form. ${ }^{12}$ The extreme floppiness of $\mathrm{LiCN}$ was discussed more recently by studying a wide domain of the potential energy surface (PES). ${ }^{5}$ For the T-shape cyanide complexes such as $\mathrm{NaCN}$ and $\mathrm{KCN}$, the electron correlation effects were found to be particularly important for determining the $\mathrm{M}-\mathrm{N}-\mathrm{C}$ angle, which became smaller by up to $10 \%$ at the third-order Møller-Plesset perturbation (MP3) level of theory. ${ }^{3}$ It is in- 
deed well known that the overall stability order among different isomers is sensitive to the basis set and the method used. The potential energy surfaces for the isomerizations of $\mathrm{HCN} \leftrightarrow \mathrm{HCN}$ and $\mathrm{LiCN} \leftrightarrow \mathrm{LiNC}$ are available, which were obtained at the second-order Møller-Plesset perturbation (MP2) and quadratically convergent configuration interaction singles-and-doubles levels of theory. ${ }^{13}$ Farantos and Tennyson ${ }^{14}$ have reported a trajectory calculation for the $\mathrm{LiCN}$ and $\mathrm{KCN}$ systems with two degrees of freedom neglecting the $\mathrm{C}-\mathrm{N}$ vibrations, where the metal atom appeared to move around the $\mathrm{CN}$ group in a chaotic way.

As for the group 11 metal complexes from $\mathrm{Cu}$ to $\mathrm{Au}$, there are several articles ${ }^{15-20}$ that can be found in the literature since the first $a b$ initio calculation of $\mathrm{CuCN}$ by Bauschlicher. $^{21}$ These studies concluded that all cyanide complexes of the group 11 metal prefer the linear cyanide structure. The photoelectron spectra of the anion ${ }^{19}$ and a gasphase milimeter-wave spectroscopy ${ }^{22}$ showed the cyanide form of $\mathrm{CuCN}$ to be the only observed conformer. While $\mathrm{AgCN}$ was also elucidated by photoelectron spectra ${ }^{19}$ no reliable experiment was reported for $\mathrm{AuCN}$. We note that the monocyanides of some other transition metal atoms and the alkaline earth atoms were also studied. Interested readers can find many useful references in a recent paper on $\mathrm{NiCN}$ by Paul et al. ${ }^{23}$

The strong ionic bonding between an alkali atom and a cyanoradical has been pointed out in ab initio calculations by Bak et $a l .{ }^{24}$ We have recently pointed out some possible sources of errors in calculating the strength of ionic bonding and showed a way to remedy such error. ${ }^{25}$

In this paper, we present high level $a b$ initio calculations for the cyanides of the groups 1 (from Li to Fr) and 11 (from $\mathrm{Cu}$ to $\mathrm{Au}$ ) metals obtained at the coupled-cluster and multireference configuration interaction (MRCI) levels using large flexible basis sets to describe both the ionic and covalent configurations. It is not easy to perform a highly accurate calculation for the MCN system by the reasons explained in this paper. However, by performing a larger scale calculation than previously attempted, we try to approach closer to the true order of chemical stability. Some of the properties of groups 1 and 11 complexes of cyanide are compared for different monovalent metal atoms. A wide range of the potential energy surfaces for the ground and a few excited states of the $\mathrm{Li}$ and $\mathrm{Na}$ complexes are calculated. The alkali cyanides have the ground state PESs which are quite flat for a fairly large domain of geometry, which leads to large amplitude vibrational motions. It is not the aim of this work to study such motions.

\section{METHOD OF COMPUTATION}

The ab initio $\mathrm{HF}$, the MRCI, the coupled-cluster (CC) method, the second-order perturbation method using MøllerPlesset (MP) partition, and the density functional theory (DFT) calculations were performed using MOLCAS, ${ }^{26}$ MOLPRO, ${ }^{27}$ and GAUSSIAN03 ${ }^{28}$ program packages. Extended atomic basis sets were optimized to describe simultaneously the covalent and ionic configurations and the ground and excited states. The all-electron basis sets used consisted of the following Gaussian type orbitals (GTOs): $13 s 8 p 3 d$ for C, $12 s 7 p 3 d$ for $\mathrm{N}, 15 s 10 p 6 d 3 f$ for $\mathrm{Li}, 15 s 10 p 5 d 1 f$ for $\mathrm{Na}$, and $16 s 12 p 6 d$ for K. These GTOs were used without contraction. Our basis for $\mathrm{Li}$ is larger than that of $\mathrm{Na}$ and that of $\mathrm{K}$ because we have calculated a larger number of the excited states for $\mathrm{LiCN}$ than $\mathrm{NaCN}$ and $\mathrm{KCN}$. The $f$ basis function does not significantly change the ground state energy for the alkali atoms. Molecular orbitals (MOs) resulting from the complete active space (CAS) self-consistent field (SCF) calculations were used for the correlation calculations at the MRCI level. State averaging was used to study the ground and excited states. In MRCI calculations, no virtual orbitals were excluded in generating the configuration state functions (CSFs). Only single excitations were allowed from the $1 s^{2}$ core of the $\mathrm{Li}$ and the $2 s^{2}$ electrons of $\mathrm{C}$ and $\mathrm{N}$, while the rest of the valence electrons were allowed to make all possible single and double excitations. For the CC calculations, all valence electrons were correlated. The effective charge of each atom for triangular geometry was calculated from two components of the dipole moment together with the condition that the sum of the effective charges should vanish. The details about dipole moment vectors will be available for the interested readers.

The relativistic effects could be significant for the $\mathrm{CN}$ complexes of heavy metal atoms. We have done comparative nonrelativistic and relativistic $\mathrm{HF}$ calculations for ( $\mathrm{K}$ to Fr)CN. We found that scalar relativistic effects shortens the $\mathrm{M}-\mathrm{C}$ and $\mathrm{M}-\mathrm{N}$ distances slightly, and increased slightly the vibrational frequencies with the largest change being $4.7 \mathrm{~cm}^{-1}$ for the bending frequency $\left(\omega_{2}\right)$ of FrCN. For K, Rb, Cs, and Fr, we used small-core (nine valence electron) energy-consistent $j$-averaged pseudopotentials of Lim et al. ${ }^{29}$ For $\mathrm{Cu}, \mathrm{Ag}$, and $\mathrm{Au}$, we have used small-core (19 valence electrons) energy-consistent pseudopotentials and the valence basis sets of Figgen et al. ${ }^{30}$ The spin-orbit coupling was neglected in the present study.

The potential energy surfaces were calculated with the MRCI method. The critical points (minima, maxima, and saddle points) were initially located and then optimized by HF, CCSD and CCSD(T) methods and subsequently by MRCI. Harmonic vibrational frequencies of selected conformers were calculated at CCSD and $\operatorname{CCSD}(\mathrm{T})$. In describing the potential energy surfaces, the Jacobian coordinates $(R, r, \theta)$ were used where $r$ is the $\mathrm{C}-\mathrm{N}$ distance with the vector direction according to $\mathrm{C} \leftarrow \mathrm{N}, R$ is the distance between the metal atom and the center of mass of $\mathrm{CN}(\mathrm{O})$ with the vector direction from $\mathrm{O}$ to $\mathrm{M}(\mathrm{O} \rightarrow \mathrm{M})$, and $\theta$ is the angle between $r$ and $R$ ( $\theta=0$ corresponds to the NCM linear geometry and $\theta=\pi$ corresponds to the MNC linear geometry).

Concerning the triatomic molecules made from three different atomic species $(A B C)$, there is no generally accepted convention for the denomination of three fundamental vibrational frequencies $\left(\nu_{1} / \nu_{2} / \nu_{3}\right)$. (Logical denomination could be according to the ascending or descending order of the frequency.) In the MCN cases, a majority of experimentalists have given the denomination according to the magnitudes following $\nu_{2}<\nu_{1}<\nu_{3}$. We are going to use this convention, although a different choice was also used in the literature. In the linear species, $\nu_{3}$ is close to the vibrational frequency of 
free $\mathrm{C}-\mathrm{N}, 2068.59 \mathrm{~cm}^{-1}$, thus representing essentially the $\mathrm{C}-\mathrm{N}$ stretching and $\nu_{1}$ can be interpreted as the stretching motion of the metal atom with respect to the $\mathrm{CN}$ moiety. As this study is not intended for calculating a large number of the vibrational levels, the $R(\mathrm{C}-\mathrm{N})$ is only slightly varied around the equilibrium distance.

\section{RESULTS AND DISCUSSION}

The cyano radical is a strongly electronegative molecule, its electron affinity being measured to be $3.862 \pm 0.004 \mathrm{eV}^{31}$ The MRCI calculation for just the $\mathrm{CN}$ and $\mathrm{CN}^{-}$molecules alone gave the electron affinity of $3.787 \mathrm{eV}$. The same accuracy could be achieved at the $\operatorname{CCSD}(\mathrm{T})$ level. According to our calculation, the equilibrium internuclear distance $\left(R_{e}\right)$ of the ground state of $\mathrm{CN}$ is $1.174 \AA$ at the MRCI level, which is slightly longer than the experimental value, $1.1718(2) \AA^{8} .^{8}$ The $R_{e}$ of $\mathrm{CN}^{-}$is calculated to be $1.176 \AA$ which agrees well with the experimental data, 1.177(4) $\AA^{31}$ The chemical bond between a metal atom and a cyano radical is mainly made by an ionic bonding through an electron transfer from the metal atom towards the cyano radical.

To fully understand the interaction between the metal atom and the cyano radical, one requires not only the information on the ground state potential surface but also that on some excited states. In the case of $\mathrm{LiCN}$ and $\mathrm{NaCN}$, three corresponding asymptotes in the increasing order in energy are $\mathrm{M}+\mathrm{CN}\left(X^{2} \Sigma^{+}\right)$, then $\mathrm{M}+\mathrm{CN}\left(A^{2} \Pi_{r}\right)$ which lies $9245.28 \mathrm{~cm}^{-1}$ higher than the former, ${ }^{8}$ followed by $\mathrm{M}^{+}$ $+\mathrm{CN}^{-}$. The energy level of $\mathrm{M}^{+}+\mathrm{CN}^{-}$is $\Delta=\mathrm{IP}(\mathrm{M})$ $-\mathrm{EA}(\mathrm{CN})$ with respect to the ground state dissociation asymptote of $\mathrm{M}+\mathrm{CN}\left(X^{2} \Sigma^{+}\right)$, where $\operatorname{IP}(\mathrm{M})$ is the ionization energy of the metal atom and $\mathrm{EA}(\mathrm{CN})$ is the electron affinity of $\mathrm{CN}$. In the case of $\mathrm{KCN}, \mathrm{RbCN}, \mathrm{CsCN}$, and $\mathrm{FrCN}$, we need to know only the lowest two potential surfaces dissociating into $\mathrm{M}+\mathrm{CN}\left(X^{2} \Sigma^{+}\right)$and $\mathrm{M}^{+}+\mathrm{CN}^{-}$, respectively. To explain the essential features of the interaction between a metal atom and the $\mathrm{CN}$ we need to see different sections of the potential energy surfaces. Figure 1 shows several sections. A section of three potential energy surfaces of $\mathrm{LiCN}$ is shown in Fig. 1(a). In this section, $r$ is fixed to 2.21 bohrs (about $117 \mathrm{pm}$ ) and $\theta$ is fixed to $\pi / 2$. The lower broken curve represents $\Delta_{\mathrm{th}}-R^{-1}$, where $\Delta_{\mathrm{th}}$ is the MRCI calculated value for $\mathrm{IP}(\mathrm{Li})-\mathrm{EA}(\mathrm{CN}), 0.048150$ hartree $(1.3102 \mathrm{eV})$. The upper broken curve is $\Delta_{\text {expt }}-R^{-1}$, where $\Delta_{\text {expt }}$ is the experimental value, 0.056209 hartree $(1.5295 \mathrm{eV})$. The ground state $\left(1^{1} A^{\prime}\right)$ is attractive ionic for $R$ up to $20.77 \mathrm{bohrs}(110 \mathrm{pm})$ and it is nonbonding, $\mathrm{M}+\mathrm{CN}\left(X^{2} \Sigma^{+}\right)$for larger $R$. The first excited state $\left(2{ }^{1} A^{\prime}\right)$ is covalent and repulsive for $R$ $<20.77$ bohrs, attractive ionic for 20.77 bohrs $<R$ $<49.3$ bohrs $(261 \mathrm{pm})$ and is nonbonding [not shown in Fig. 1(a)], $\mathrm{Li}+\mathrm{CN}\left(A^{2} \Pi_{r}\right)$ for larger distances. The second excited state $\left(3{ }^{1} A^{\prime}\right)$ is repulsive for $R<49.3$ bohrs and attractive ionic [not shown in Fig. 1(a)] for larger distances to become $\mathrm{M}^{+}+\mathrm{CN}^{-}$at infinity. The ionic-covalent avoided crossings occur punctually (i.e., well localized), and the energy splittings (or gaps) are very small as was reported in the case of $\mathrm{NaCN}{ }^{25}$ The ionic parts of the potential energy surfaces closely follow the $\Delta_{\mathrm{th}}-R^{-1}$ function (considering the bond as a point-charge dipole) down to relatively short distances: in Fig. 1(a), the calculated curve is 0.000188 hartree $(0.005 \mathrm{eV})$ lower than the point-charge model at $10 \mathrm{bohrs}$, 0.000094 hartree $(0.003 \mathrm{eV})$ higher at 20 bohrs, and 0.000031 hartree (less than $0.001 \mathrm{eV}$ ) higher at 30 bohrs. In reality, the ionic parts should rather follow the upper broken curve. As a consequence, the ionic-covalent avoided crossing distances should be located at smaller $R$ 's than the above mentioned distances. The origin and the consequences (spectroscopic properties and reaction dynamic properties) of the inaccuracy of the $a b$ initio and DFT calculations have been explained earlier. $^{25}$

Different sections of the ground state potential energy surface are reported in Fig. 1(b). Here, $r$ is fixed and $R$ and $\theta$ are varied. In Figs. 1(a) and 1(b), we have used six $a^{\prime}$ MOs and two $a^{\prime \prime}$ MOs to distribute six valence electrons (one from $\mathrm{Li}$, two from $\mathrm{C}$, and three from $\mathrm{N}$ ) in the CASSCF (616 CSFs) then all possible single and double substitutions were taken into account in the MRCI (6 104070 CSFs). We can see in Fig. 1(b) two stable conformers, linear LiCN and LiNC. The LiNC linear conformer appeared to be lower than the LiCN linear conformer by $0.0469 \mathrm{eV}$ at this level of MRCI (which we will call MRCI-1). The potential energy changes little on bending the $\mathrm{Li}-\mathrm{N}-\mathrm{C}$ angle around $\theta=180^{\circ}$. Bending the Li-C-N angle around $\theta=0^{\circ}$ changes the potential energy more, resulting in a relatively higher bending frequency than in the former case. In a second MRCI, we have used five $a^{\prime}$ MOs and two $a^{\prime \prime}$ MOs to distribute six valence electrons in the CASSCF (260 CSFs), and then all possible single and double substitutions were considered. Furthermore, two more electrons from $5 a^{\prime}$ MO that correspond to a polarized $2 s^{2}$ atomic orbital of the carbon atom were allowed to make all possible single substitutions, which made the dimension of CI to be 13776392 (we will call this MRCI2 ). The result is slightly different, suggesting a significant correlation effect between the $\mathrm{C}\left(2 s^{2}\right)$ electrons and other valence electrons. A triangular $C_{s}$ geometry ( $\mathrm{T}$ shape) with $\eta^{2}$ coordination appeared to be the most stable form, and the linear $\mathrm{LiCN}$ is $0.0125 \mathrm{eV}$ higher than the former but is stable because of a potential barrier connecting these two conformers. The linear LiNC is unstable as there exists no potential barrier separating this from the triangular form. The lowest energy of the LiNC is $0.0333 \mathrm{eV}$ higher than the triangular form. However, the triangular form has a much lower bending frequency in comparison with the linear $\mathrm{LiCN}$ as in the MRCI-1.

Our results as well as former theoretical studies demonstrate the difficulty of deciding the relative stability of three different conformers for LiCN complex. The relative stabilities of different conformers MCN are reported in Table I. The result differs according to the method of calculation, the atomic and molecular basis set and the level of correlation effect taken into account. The HF method does not give any stable triangular form but gives the linear LiNC lower than the linear LiCN, the transition state connecting these two forms being triangular. The inclusion of the electron correlation effect at the CCSD level gives a stable triangular form separated from the linear LiNC by a very low potential barrier. Inclusion of the higher order correlation effect by the 


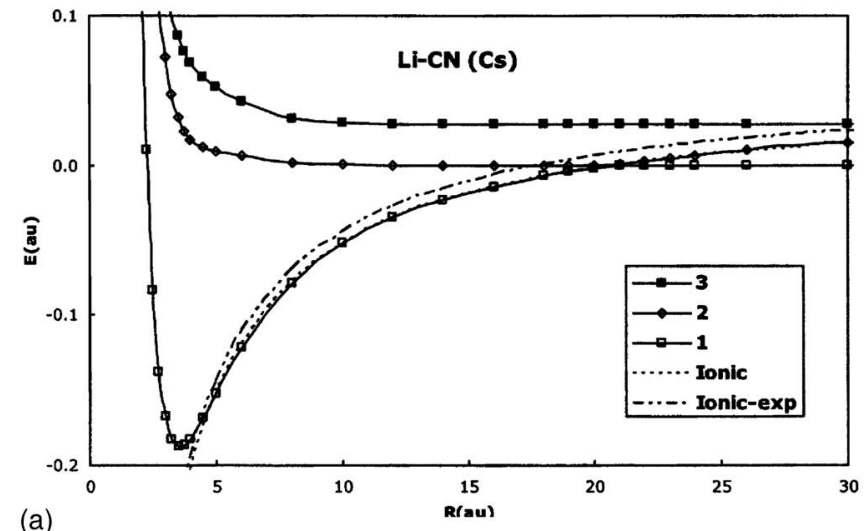

(a)
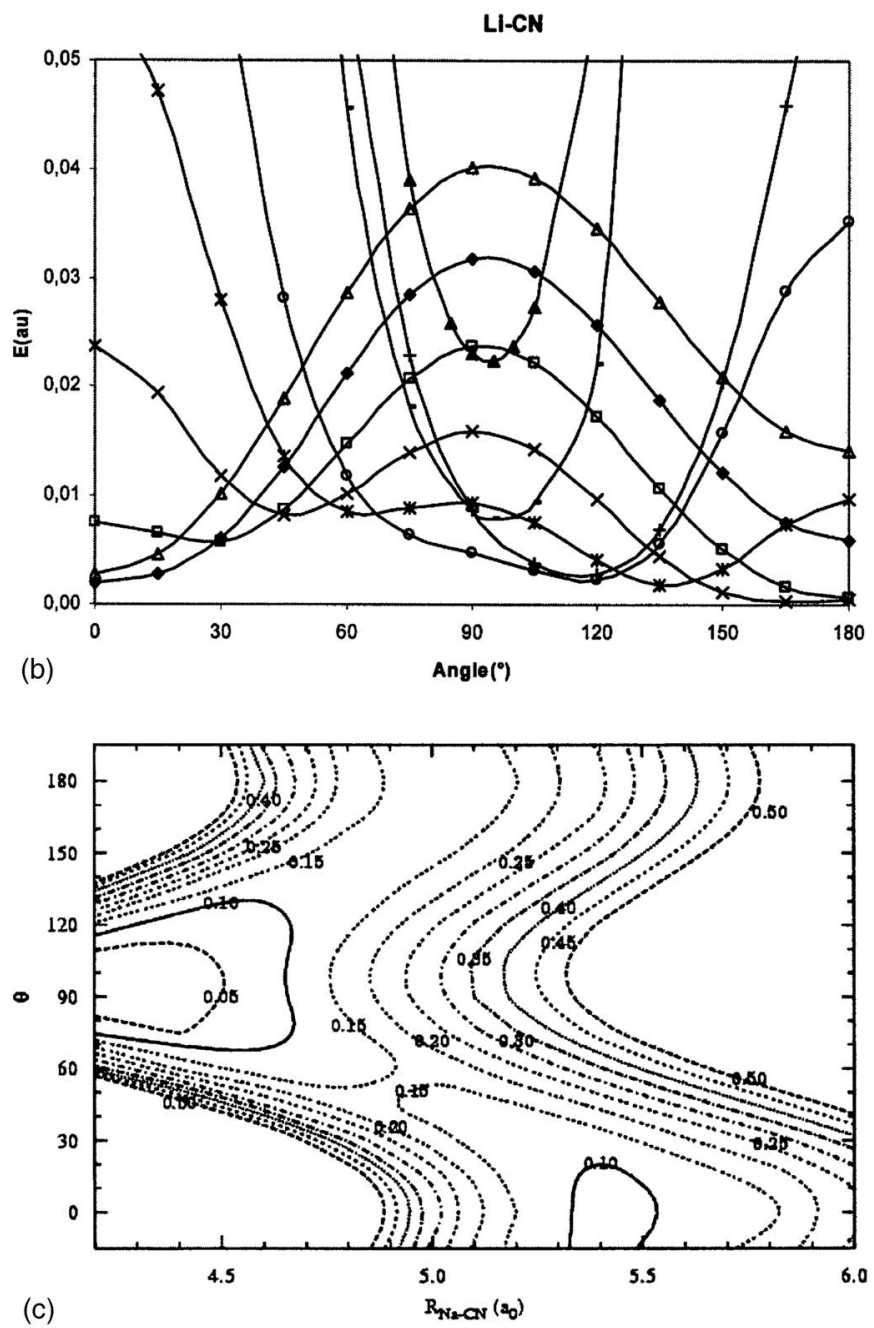

$\operatorname{CCSD}(\mathrm{T})$ method gives the triangular form practically at the same energy level as the linear LiNC form. Considering the same tendency of relative energy change in the MRCI- 1 and MRCI-2, we guess that more extensive inclusion of the correlation effect would give the triangular form as the lowest energy form and the linear LiNC should not be a stable form. The LiNC conformer or the triangular conformer is easy to bend around the $\mathrm{Li}-\mathrm{N}-\mathrm{C}$ angle of $150^{\circ}$ (MRCI-2) so it is most likely that those two forms cannot be distinguished in reality when the dynamic aspect ${ }^{13}$ is taken into account. Table I shows that the ground state of the cyanides of alkali

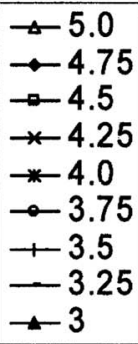

Fion of potential energy surfaces of $\mathrm{LiCN}$. The $\mathrm{C}-\mathrm{N}$ distance $(r)$ is fixed to 2.21 bohrs, the Jacobian angle $(\theta)$ is $\pi / 2$, and $R$ in bohr is the distance between $\mathrm{Li}$ and the center of mass of $\mathrm{CN}$. Broken curves for $\Delta_{\text {expt }}-R^{-1}$ (upper curve) and $\Delta_{\mathrm{th}}-R^{-1}$ (lower curve) are the point-charge curves (see text). (b) A section of the ground state potential energy surface where $r(\mathrm{C}-\mathrm{N})=2.21$ bohrs; $R$ (legend, in bohr) and $\theta(\mathrm{ab}-$ scissa, in degree) are varied. The energy scale is with respect to the lowest potential energy of the LiNC linear complex. (c) Isopotential (in eV) contour map for the ground state potential energy surface of $\mathrm{NaCN}$ in Jacobian coordinates with $r(\mathrm{C}-\mathrm{N})=2.21$ bohrs. Potential energies are with respect to the minimum value found in a triangular geometry. 
TABLE I. Relative energy levels of the MCN complexes and the transition states (TSs) in $\mathrm{kJ} / \mathrm{mol}(1 \mathrm{eV}$ $=96.4853 \mathrm{~kJ} / \mathrm{mol}$ and 1 hartree $=27.2107 \mathrm{eV})$. Saddle points are indicated by "\#" and nonexistent data are indicated by "—."

\begin{tabular}{|c|c|c|c|c|c|c|}
\hline Atom & Method & MCN (linear) & TS1 & $\mathrm{M}[\mathrm{CN}]\left(\eta^{2}\right)$ & TS2 & MNC (linear) \\
\hline \multirow[t]{6}{*}{$\mathrm{Li}$} & $\mathrm{HF}$ & 25.3 & 39.2 & - & - & 0 \\
\hline & CCSD & 10.4 & 22.9 & 0.4 & 3.4 & 0 \\
\hline & $\operatorname{CCSD}(\mathrm{T})$ & 8.8 & 20.6 & 0.1 & 2.9 & 0 \\
\hline & MRCI-1 & 4.5 & & - & - & 0 \\
\hline & MRCI-2 & 1.3 & & 0 & - & $3.2(\#)$ \\
\hline & MP2- $4^{\mathrm{a}}$ & 6.9 & & 1.2 & & 0 \\
\hline \multirow[t]{3}{*}{$\mathrm{Na}$} & $\mathrm{HF}$ & 16.8 & 22.5 & 0 & 2.5 & 2.2 \\
\hline & $\operatorname{CCSD}(\mathrm{T})$ & 10.1 & 15.8 & 0 & 11.2 & 11.1 \\
\hline & MRCI & 6.7 & & 0 & & 11.5 \\
\hline \multirow[t]{2}{*}{ K } & $\mathrm{HF}$ & 21.6 & 22.7 & 0 & - & $4.1(\#)$ \\
\hline & $\operatorname{CCSD}(\mathrm{T})$ & 18.3 & 19.3 & 0 & - & 13.0(\#) \\
\hline \multirow[t]{2}{*}{$\mathrm{Rb}$} & $\mathrm{HF}$ & 21.6 & 22.2 & 0 & - & 22.2(\#) \\
\hline & $\operatorname{CCSD}(\mathrm{T})$ & 18.3 & 18.8 & 0 & - & $12.5(\#)$ \\
\hline \multirow[t]{2}{*}{ Cs } & $\mathrm{HF}$ & 22.0 & 22.1 & 0 & - & 3.9(\#) \\
\hline & $\operatorname{CCSD}(\mathrm{T})$ & 18.6 & 18.8 & 0 & - & 11.3(\#) \\
\hline \multirow[t]{2}{*}{$\mathrm{Fr}$} & $\mathrm{HF}$ & 21.4 & 21.5 & 0 & - & 4.1(\#) \\
\hline & $\operatorname{CCSD}(\mathrm{T})$ & 18.5 & 18.5 & 0 & - & $11.9(\#)$ \\
\hline \multirow[t]{2}{*}{$\mathrm{Cu}$} & $\mathrm{HF}$ & 0 & - & 39.4(\#) & - & 7.8 \\
\hline & $\operatorname{CCSD}(\mathrm{T})$ & 0 & - & $57.0(\#)$ & - & 38.7 \\
\hline \multirow[t]{2}{*}{$\mathrm{Ag}$} & $\mathrm{HF}$ & 0 & - & 31.2(\#) & - & 27.8 \\
\hline & $\operatorname{CCSD}(\mathrm{T})$ & 0 & - & 63.9(\#) & - & 59.9 \\
\hline \multirow[t]{2}{*}{$\mathrm{Au}$} & $\mathrm{HF}$ & 0 & - & 88.7(\#) & - & 69.6 \\
\hline & $\operatorname{CCSD}(\mathrm{T})$ & 0 & - & 131.0(\#) & - & 109.2 \\
\hline
\end{tabular}

${ }^{\mathrm{a}}$ From Ref. 5.

stability and the barrier height also increase as the level of the correlation effect included in the calculation becomes higher in the order $\mathrm{HF} \rightarrow \mathrm{CCSD} \rightarrow \mathrm{CCSD}(\mathrm{T})$.

The equilibrium internuclear distances are reported in Table II. It appears that the $\mathrm{C}-\mathrm{N}$ distances in the metal complexes vary little from one complex to another and are found between 117 and $118 \mathrm{pm}$, about the bond length of free $\mathrm{CN}$ (117.2 pm) or $\mathrm{CN}^{-}(117.7 \mathrm{pm})$. This is in agreement with Leroi and Klemperer's $\omega_{3}$ observations. ${ }^{7}$ In the triangular conformer of the alkali cyanide, the $\mathrm{M}-\mathrm{N}$ distance is smaller than the $\mathrm{M}-\mathrm{C}$ distance. The scalar relativistic effect in $\mathrm{HF}$ approximation shortens the $\mathrm{M}-\mathrm{N}$ distance insignificantly (by a maximum of $2 \mathrm{pm}$ in $\mathrm{FrCN}$ ) and shortens the $\mathrm{M}-\mathrm{C}$ distance slightly (by a maximum of $10 \mathrm{pm}$ in $\mathrm{FrCN}$ ). It is interesting to note that the correlation effect enlarges systematically the $\mathrm{M}-\mathrm{N}$ and $\mathrm{C}-\mathrm{N}$ distances while it shortens the $\mathrm{M}-\mathrm{C}$ distance for the triangular $\left(\eta^{2}\right)$ conformers, and it enlarges the $\mathrm{C}-\mathrm{N}$ distance and shortens the $\mathrm{M}-\mathrm{C}$ distance for the linear MCN conformers. It is as if the electron correlation made the steric repulsion from the $\mathrm{C}\left(2 \mathrm{~s}^{2}\right)$ electron pair weaker. The correlation effect makes the $\mathrm{C}-\mathrm{N}$ distances larger and the $\mathrm{M}-\mathrm{C}$ distances smaller for the linear $\mathrm{MCN}$ noble metal complexes as in the alkali complexes. The rotational frequencies are reported in Table III. Our calculated values are in good agreement with the experimentally measured values.

The harmonic vibrational frequencies of $\mathrm{MCN}$ com- plexes are reported in Table IV. Concerning the discrepancy between Leroi and Klemperer's $\nu_{1}$ values ${ }^{7}$ and those of Ismail et al., ${ }^{9}$ our result is closer to the latter. The decreasing tendency of the bending frequency $\left(\omega_{1}\right)$ for the $\mathrm{Li} \rightarrow \mathrm{Na}$ $\rightarrow \mathrm{K} \rightarrow \mathrm{Rb} \rightarrow \mathrm{Cs} \rightarrow$ Fr suite is in parallel with the decreasing bond energy or decreasing curvature of the potential energy surface near the equilibrium geometry for the same suite. For the doubly degenerate bending frequency $\left(\omega_{2}\right)$, the low stretching frequency $\left(\omega_{1}\right)$ and the high stretching frequency $\left(\omega_{3}\right)$ of the linear $\mathrm{MCN}$ of the $\mathrm{Cu} \rightarrow \mathrm{Ag} \rightarrow \mathrm{Au}$ suite, the $\mathrm{AgCN}$ has the smallest values and the $\mathrm{CuCN}$ has the largest values. A DFT calculation by Dietz et $a .^{20}$ also gave the same order for the vibrational frequencies. The $\omega_{1}$ for $\mathrm{AgCN}$ was observed to be smaller than that of $\mathrm{CuCN}$ in the photoelectron detachment spectra of anions. ${ }^{19}$ This order indirectly suggests smaller $\mathrm{M}-\mathrm{CN}$ bond energy for the $\mathrm{AgCN}$ than those of $\mathrm{CuCN}$ and $\mathrm{AuCN}$.

The MCN complexes have large dipole moments created by the electron transfer from the metal atom to the $\mathrm{CN}$ group. The dipole moment of the $\mathrm{NaCN}$ is shown in Fig. 2. In this figure, $r$ is fixed to 2.21 bohrs, $R$ is fixed to 4.50 bohrs and only $\theta$ is varied. In this figure, the origin of the coordinates is placed at the center of mass of $\mathrm{CN}$, the arrowheads point to the direction of the Li nucleus (indicated by " $x$ "), and the lengths of vector are proportional to the amplitudes of dipole moment. Then we find that the dipole 
TABLE II. Equilibrium bond lengths of the triangular $\eta^{2}\left(\mathrm{M}[\mathrm{CN}]\right.$ ) and the linear $\eta^{1} \mathrm{MCN}$ complexes (in pm).

\begin{tabular}{|c|c|c|c|c|c|}
\hline Metal & Conformer & Method & $R(\mathrm{M}-\mathrm{C})$ & $R(\mathrm{M}-\mathrm{N})$ & $R(\mathrm{C}-\mathrm{N})$ \\
\hline \multirow[t]{3}{*}{$\mathrm{Li}$} & $\eta^{2}$ & $\operatorname{CCSD}(\mathrm{T})$ & 213 & 185 & 118 \\
\hline & & MRCI-2 & 209 & 186 & 117 \\
\hline & & Expt. $^{\mathrm{a}}$ & & 176.0 & 116.8 \\
\hline \multirow[t]{3}{*}{$\mathrm{Na}$} & & $\operatorname{CCSD}(\mathrm{T})$ & 239 & 223 & 118 \\
\hline & & MRCI & 272 & 226 & 117 \\
\hline & & Expt. $^{b}$ & 238 & 223 & 117 \\
\hline \multirow[t]{3}{*}{ K } & & $\operatorname{CCSD}(\mathrm{T})$ & 273 & 255 & 118 \\
\hline & & MRCI & 286 & 259 & 117 \\
\hline & & Expt. $^{c}$ & 272 & 255 & 117 \\
\hline $\mathrm{Rb}$ & & $\operatorname{CCSD}(\mathrm{T})$ & 286 & 268 & 118 \\
\hline Cs & & $\operatorname{CCSD}(\mathrm{T})$ & 303 & 282 & 118 \\
\hline $\mathrm{Fr}$ & & $\operatorname{CCSD}(\mathrm{T})$ & 309 & 289 & 118 \\
\hline \multirow[t]{2}{*}{$\mathrm{Li}$} & $\eta^{1}$ & $\operatorname{CCSD}(\mathrm{T})$ & 192 & & 117 \\
\hline & & MRCI & 192 & & 117 \\
\hline \multirow[t]{2}{*}{$\mathrm{Na}$} & & $\operatorname{CCSD}(\mathrm{T})$ & 225 & & 117 \\
\hline & & MRCI & 291 & & 117 \\
\hline K & & $\operatorname{CCSD}(\mathrm{T})$ & 260 & & 117 \\
\hline $\mathrm{Rb}$ & & $\operatorname{CCSD}(\mathrm{T})$ & 273 & & 117 \\
\hline Cs & & $\operatorname{CCSD}(\mathrm{T})$ & 288 & & 117 \\
\hline $\mathrm{Fr}$ & & $\operatorname{CCSD}(\mathrm{T})$ & 294 & & 117 \\
\hline \multirow[t]{4}{*}{$\mathrm{Cu}$} & & $\operatorname{CCSD}(\mathrm{T})$ & 184 & & 117 \\
\hline & & $\mathrm{BP} 86 / \mathrm{TZP}^{\mathrm{d}}$ & 178 & & 117 \\
\hline & & $\operatorname{CCSD}(\mathrm{T})^{\mathrm{e}}$ & 186 & & 118 \\
\hline & & Expt. $^{\mathrm{f}}$ & 183 & & 116 \\
\hline \multirow[t]{2}{*}{$\mathrm{Ag}$} & & $\operatorname{CCSD}(\mathrm{T})$ & 203 & & 117 \\
\hline & & $\mathrm{BP} 86 / \mathrm{TZP}^{\mathrm{d}}$ & 201 & & 117 \\
\hline \multirow[t]{2}{*}{$\mathrm{Au}$} & & $\operatorname{CCSD}(\mathrm{T})$ & 192 & & 117 \\
\hline & & BP86/TZP ${ }^{\mathrm{d}}$ & 192 & & 117 \\
\hline
\end{tabular}

${ }^{\mathrm{a}}$ From Ref. 10, supposedly LiNC linear.

${ }^{\mathrm{b}}$ From Ref. 10.

${ }^{c}$ From Ref. 10, triangular structure.

${ }^{\mathrm{d}}$ From Ref. 20.

${ }^{\mathrm{e}}$ From Ref. 19.

${ }^{\mathrm{f}}$ From Ref. 22.

moment vectors cut the line segment between the $\mathrm{C}$ and $\mathrm{N}$ atoms. This proves that the dipole moments can be simulated very well by two point charges (a point-charge dipole), one placed at the Na nucleus and the other one placed on the line connecting $\mathrm{C}$ and $\mathrm{N}$ atoms which is close to the center of mass of $\mathrm{CN}$.

The molecular dipole moment can also be simulated by a three-point-charge system each placed at the center of atom (nucleus) according to the analysis explained in Sec. II. In the triangular $\mathrm{LiCN}$ case, for example, $\mathrm{Li}$ has an effective charge of +0.766 , $\mathrm{C}$ has -0.440 , and $\mathrm{N}$ has -0.327 in the MRCI, as can be seen in Table $\mathrm{V}$ where the effective charges for the triangular complexes of $[(\mathrm{Li})-(\mathrm{Cs})] \mathrm{CN}$ are calculated. For the linear molecules, $[(\mathrm{Cu})-(\mathrm{Au})] \mathrm{CN}$, we cannot obtain the effective charges for all three atoms but two ef- fective charges (e.g., those of $\mathrm{C}$ and $\mathrm{N}$ in this table) can be expressed in terms of the unknown third atomic charge (given by the positive metal atomic charges $\alpha, \beta$, and $\gamma$ in this table). Larger negative charge of the $\mathrm{C}$ atom in comparison with the $\mathrm{N}$ atom is in agreement with Fig. 2, where we see the negative charge shifts towards the $\mathrm{C}$ atom from the midpoint of $\mathrm{C}-\mathrm{N}$. This may contradict the commonly accepted notion that the $\mathrm{N}$ atom is more electronegative than the $\mathrm{C}$ atom, but the effective charge of $\mathrm{C}$ is more negative than $\mathrm{N}$ in $\mathrm{CN}^{-}$anion due to the larger electron affinity of $\mathrm{C}$ than that of $\mathrm{N}$. We can compare this with the MCO cases. ${ }^{32}$ The small dipole moment of the $\mathrm{CO}$ shows the carbon atom negative although the electron affinity of oxygen atom is larger than that of the carbon atom. In making a complex with a metal atom, the metal electron has a larger probability 
TABLE III. Rotational constants of the MCN (in MHz).

\begin{tabular}{|c|c|c|c|c|c|}
\hline Metal & Conformer & Method & $A$ & $B$ & $C$ \\
\hline \multirow[t]{2}{*}{${ }^{7} \mathrm{Li}$} & Linear LiNC & Present & & 13061 & \\
\hline & & Expt. $^{\mathrm{a}}$ & & 13293 & \\
\hline \multirow[t]{2}{*}{${ }^{63} \mathrm{Cu}$} & Linear MCN & Present & & 4192 & \\
\hline & & Expt. $^{b}$ & & 4225 & \\
\hline${ }^{107} \mathrm{Ag}$ & & Present & & 3233 & \\
\hline${ }^{197} \mathrm{Au}$ & & Present & & 3205 & \\
\hline \multirow[t]{2}{*}{${ }^{23} \mathrm{Na}$} & Triangular $\left(\eta^{2}\right)$ & Present & 56948 & 8310 & 7252 \\
\hline & & Expt. $^{c}$ & 57922 & 8369 & 7273 \\
\hline \multirow[t]{2}{*}{${ }^{39} \mathrm{~K}$} & & Present & 57245 & 4907 & 4519 \\
\hline & & Expt. $^{\mathrm{d}}$ & 58266 & 4940 & 4536 \\
\hline${ }^{85} \mathrm{Rb}$ & & Present & 57361 & 3481 & 3281 \\
\hline${ }^{133} \mathrm{Cs}$ & & Present & 57867 & 2838 & 2706 \\
\hline${ }^{223} \mathrm{Fr}$ & & Present & 57555 & 2538 & 2431 \\
\hline
\end{tabular}

${ }^{\mathrm{a}}$ From Ref. 10.

${ }^{\mathrm{b}}$ From Ref. 22.

${ }^{c}$ From Ref. 10

${ }^{\mathrm{d}}$ From Ref. 11.

to stay around the carbon atom than around the oxygen atom. One may note that the MRCI gives a larger dipole moment than the $\operatorname{CCSD}(\mathrm{T})$ method. Although the dipole moment increases for the suite $\mathrm{Li} \rightarrow \mathrm{Fr}$, it is about constant for $\mathrm{Rb}$ $\rightarrow$ Fr. Consequently, the effective charge of the metal atom (positive) shows a curious tendency. It increases for the suite $\mathrm{Li} \rightarrow \mathrm{K}$ then decreases for $\mathrm{K} \rightarrow \mathrm{Fr}$, contrary to the commonly accepted electropositivity order. The effective charges of the nitrogen and carbon atoms, both negative, show the opposite tendency. The similar tendency is observed for the Mulliken charges derived from the natural MOs. Besides, the special relativistic effects significantly reduce ionization potentials for heavy elements. The internuclear distances, which will be less affected by the relativistic effect for these molecules, are probably the major factor for this deviation from the simple trend because the all-electron nonrelativistic HF calculation gave the same tendency. For the linear MCN complexes, the effective charge of the carbon atom should be more negative than that of the nitrogen atom if the effective charge of the metal atom is larger than a given positive number, that is, $Q_{M}>2 \mu\left(2 r_{\mathrm{MC}}+r_{\mathrm{CN}}\right)^{-1}$, where $Q_{M}$ is the effective charge of the metal atom, $\mu$ is the dipole moment, $r_{\mathrm{MC}}$ is the distance between the metal atom and the carbon atom, and $r_{\mathrm{CN}}$ is the distance between the carbon atom and the nitrogen atom. This critical charge is 0.631 for $\mathrm{Cu}, 0.618$ for $\mathrm{Ag}$, and 0.509 for $\mathrm{Au}$ in atomic unit. The effective charges of the triangular forms calculated around the linear form suggest that this condition is satisfied for $\mathrm{Cu}$ and $\mathrm{Ag}$ but not for $\mathrm{Au}$. If on the contrary the metal charge is smaller than the critical value, then the nitrogen atom should have more negative charge than that of the carbon atom. For the $[(\mathrm{Cu})-(\mathrm{Au})] \mathrm{CN}$ linear complexes the AuCN has the smallest dipole moment and $\mathrm{AgCN}$ has the largest one. This is believed to be connected with the large relativistic effect of the AuCN complex.
The potential contour map for $\mathrm{NaCN}$ is reported in Fig. $1(\mathrm{c})$, where $r(\mathrm{C}-\mathrm{N})$ is fixed to 2.21 bohrs and $R$ and $\theta$ were varied. Here, $\theta$ should vary between $0^{\circ}$ and $180^{\circ}$. The data outside this domain were added for a technical reason: that the equipotential lines should cut the $\theta=0^{\circ}$ and $\theta=180^{\circ}$ lines orthogonally. At very low collision energies, as the distance $(R)$ between the $\mathrm{Na}$ atom and the center of mass of $\mathrm{CN}$ decreases from $\infty$, the $\mathrm{CN}$ group should approach the sodium atom with the nitrogen atom heading to the sodium atom to follow the lowest energy path $\left(\theta \approx 180^{\circ}\right)$. At small $R$, the $\mathrm{CN}$ moiety rotates around the sodium atom to make the triangular conformer. Along the path with the carbon atom heading to the sodium atom $\left(\theta \approx 0^{\circ}\right)$, there exists a potential barrier. The same is valid for other MCN complexes of alkali atoms.

\section{CONCLUSION}

In this paper, we have studied the molecular properties of the MCN complexes and surveyed the potential energy surfaces for the collision between the $\mathrm{CN}$ group and a metal atom $\mathrm{M}$ (groups 1 and 11). We find that the triangular conformer generally has the lowest energy in comparison with the linear cyanide and linear isocyanide for the complexes of alkali atoms. In the triangular complexes, the $\mathrm{M}-\mathrm{N}$ distance is significantly shorter than the $\mathrm{M}-\mathrm{C}$ distance. The potential barrier connecting the triangular form and the linear cyanide form decreases according to the order $\mathrm{Li} \rightarrow \mathrm{Fr}$. The electron correlation effect enlarges the $\mathrm{M}-\mathrm{N}$ and $\mathrm{C}-\mathrm{N}$ distances and shortens the $\mathrm{M}-\mathrm{C}$ distance for the alkali complexes, which can be attributed to a diminishment of the steric repulsion of the polarized nonbonding electron pair of the carbon atom. The MCN complexes have large dipole moments. The effective charge of the metal atom shows a curious tendency, in- 
TABLE IV. Harmonic vibrational frequencies $\left(\right.$ in $\mathrm{cm}^{-1}$ ) of $\mathrm{MCN}$ calculated by $\mathrm{CCSD}(\mathrm{T})$ method compared with other data.

\begin{tabular}{|c|c|c|c|c|c|}
\hline Metal & Conformer & Method & $\omega_{2}$ & $\omega_{1}$ & $\omega_{3}$ \\
\hline \multirow[t]{4}{*}{${ }^{7} \mathrm{Li}$} & \multirow[t]{2}{*}{ Linear LiNC } & $\operatorname{CCSD}(\mathrm{T})$ & 113 & 706 & 2082 \\
\hline & & Expt. $^{a}$ & 120 & 681 & 2080 \\
\hline & Triangular $\eta^{2}$ & $\operatorname{CCSD}(\mathrm{T})$ & 181 & 656 & 2040 \\
\hline & Linear LiCN & $\operatorname{CCSD}(\mathrm{T})$ & 180 & 623 & 2142 \\
\hline \multirow[t]{4}{*}{${ }^{23} \mathrm{Na}$} & \multirow[t]{4}{*}{ Triangular $\eta^{2}$} & $\operatorname{CCSD}(\mathrm{T})$ & 187 & 379 & 2043 \\
\hline & & Expt. $^{\mathrm{b}}$ & 239 & & 2176 \\
\hline & & Expt. $^{a}$ & 168 & 368 & 2047 \\
\hline & & Expt. $^{c}$ & 179 & & \\
\hline \multirow[t]{4}{*}{${ }^{39} \mathrm{~K}$} & & $\operatorname{CCSD}(\mathrm{T})$ & 166 & 299 & 2048 \\
\hline & & Expt. $^{\mathrm{b}}$ & 207 & & 2158 \\
\hline & & Expt. $^{\mathrm{a}}$ & 139 & 288 & 2050 \\
\hline & & Expt. $^{\mathrm{c}}$ & 157 & & \\
\hline${ }^{85} \mathrm{Rb}$ & & $\operatorname{CCSD}(\mathrm{T})$ & 153 & 255 & 2048 \\
\hline${ }^{133} \mathrm{Cs}$ & & $\operatorname{CCSD}(\mathrm{T})$ & 134 & 234 & 2047 \\
\hline${ }^{223} \mathrm{Fr}$ & & $\operatorname{CCSD}(\mathrm{T})$ & 136 & 224 & 2045 \\
\hline \multirow[t]{4}{*}{${ }^{63} \mathrm{Cu}$} & Linear MCN & $\operatorname{CCSD}(\mathrm{T})$ & 336 & 519 & 2190 \\
\hline & & BP86/TZP ${ }^{\mathrm{d}}$ & 255 & 512 & 2177 \\
\hline & & $\operatorname{CCSD}(T)^{\mathrm{e}}$ & 225 & 453 & 2159 \\
\hline & & Expt. $^{\mathrm{f}}$ & 270 & 478 & \\
\hline \multirow[t]{3}{*}{${ }^{107} \mathrm{Ag}$} & & $\operatorname{CCSD}(\mathrm{T})$ & 186 & 395 & 2168 \\
\hline & & BP86/TZP ${ }^{d}$ & 224 & 397 & 2171 \\
\hline & & Expt. $^{\mathrm{e}}$ & & 390 & \\
\hline \multirow[t]{2}{*}{${ }^{197} \mathrm{Au}$} & & $\operatorname{CCSD}(\mathrm{T})$ & 259 & 478 & 2179 \\
\hline & & BP86/TZP ${ }^{d}$ & 292 & 475 & 2176 \\
\hline
\end{tabular}

${ }^{\mathrm{a}}$ From Ref. 9.

${ }^{\mathrm{b}}$ From Ref. 7.

${ }^{\mathrm{c}}$ From Ref. 10.

${ }^{\mathrm{d}}$ From Ref. 20.

${ }^{\mathrm{e}}$ From Ref. 19.

${ }^{\mathrm{f}}$ From Ref. 22.

creasing for the suite $\mathrm{Li} \rightarrow \mathrm{K}$ then decreasing for $\mathrm{K} \rightarrow \mathrm{Fr}$. The carbon atom has a larger negative charge than that of the nitrogen atom in the alkali complexes. For a very low energy collision between the alkali atom and the $\mathrm{CN}$ group, it is energetically most probable that the nitrogen atom of the $\mathrm{CN}$ group makes a head-on collision with the metal atom, then the $\mathrm{CN}$ group rotates at short distances to assume a triangular form. The noble metal atoms prefer the linear cyanide form to the linear isocyanide form. The barrier connecting those two conformers increases according to the order $\mathrm{Cu}<\mathrm{Ag}$ $<\mathrm{Au}$. The vibrational frequencies show minima for the $\mathrm{AgCN}$ in comparison with $\mathrm{CuCN}$ and $\mathrm{AuCN}$, suggesting probably the smallest bond energy for $\mathrm{AgCN}$ among those complexes. The $r_{e}(\mathrm{C}-\mathrm{N})$ varies little for different species

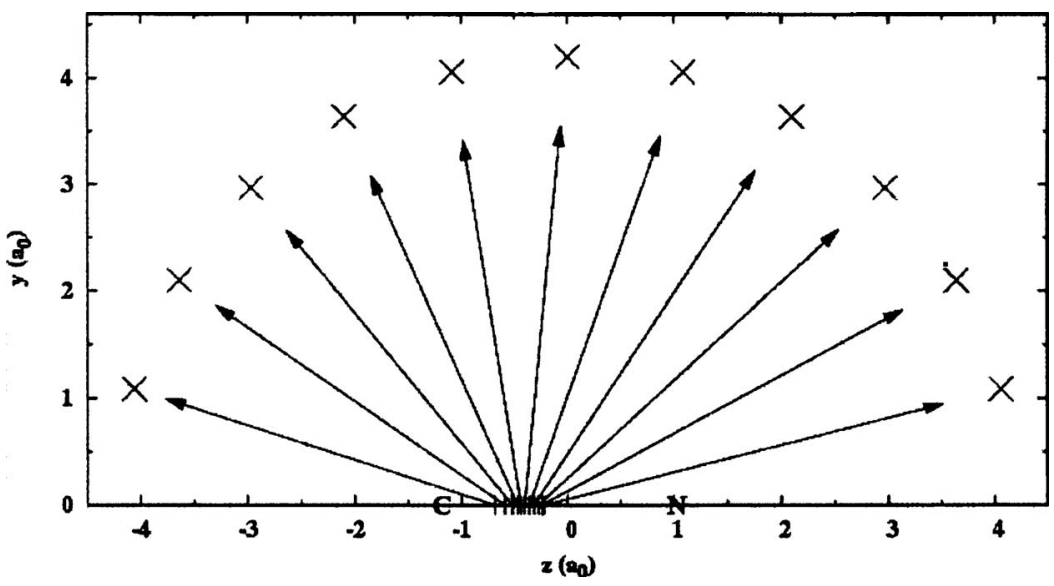

FIG. 2. Dipole moment vectors of $\mathrm{LiCN}$ as a function of $\theta$ with $r(\mathrm{C}-\mathrm{N})=2.21$ bohrs and $R=4.50$ bohrs. The $\mathrm{CN}$ group lies along the abscissa, the $\mathrm{C} \rightarrow \mathrm{N}$ direction is taken positive, with its center of mass coinciding with the origin of coordinates. The arrowheads of the dipole moment vectors point to the direction of the Li nucleus (indicated by " $x ")$, and the lengths of vector are proportional to the amplitudes of dipole moment. 
TABLE V. Dipole moments and effective atomic charges of the MCN, triangular $\left(\eta^{2}\right)$ complexes for $[(\mathrm{Li})-$ $(\mathrm{Cs})] \mathrm{CN}$, and linear complexes for $[(\mathrm{Cu})-(\mathrm{Ag})] \mathrm{CN}$, calculated from the dipole moment (in atomic units, 1 a.u. of dipole moment is equivalent to $2.54175 \mathrm{D}$ ). The effective charges $\alpha$, $\beta$, and $\gamma$ should be real numbers between 0 and 1 .

\begin{tabular}{llllcc}
\hline \hline Metal & Method & DM & $Q(\mathrm{M})$ & $Q(\mathrm{~N})$ & $Q(\mathrm{C})$ \\
\hline $\mathrm{Li}$ & $\mathrm{CCSD}(\mathrm{T})$ & 2.6775 & 0.765 & -0.363 & -0.402 \\
& MRCI-2 & 2.7644 & 0.766 & -0.327 & -0.440 \\
$\mathrm{Na}$ & $\mathrm{CCSD}(\mathrm{T})$ & 3.4757 & 0.820 & -0.372 & -0.448 \\
& MRCI & 3.6313 & 0.843 & -0.321 & -0.522 \\
$\mathrm{~K}$ & $\mathrm{CCSD}(\mathrm{T})$ & 4.0444 & 0.828 & -0.368 & -0.460 \\
& MRCI & 4.4963 & 0.884 & -0.317 & -0.567 \\
$\mathrm{Rb}$ & $\mathrm{CCSD}(\mathrm{T})$ & 4.1697 & 0.812 & -0.358 & -0.454 \\
$\mathrm{Cs}$ & $\mathrm{CCSD}(\mathrm{T})$ & 4.2667 & 0.784 & -0.342 & -0.442 \\
$\mathrm{Fr}$ & $\mathrm{CCSD}(\mathrm{T})$ & 4.2761 & 0.768 & -0.333 & -0.435 \\
$\mathrm{Cu}$ & $\mathrm{CCSD}(\mathrm{T})$ & 2.8911 & $\alpha$ & $1.573 \alpha-1.308$ & $1.308-2.573 \alpha$ \\
$\mathrm{Ag}$ & $\mathrm{CCSD}(\mathrm{T})$ & 3.0535 & $\beta$ & $1.735 \beta-1.381$ & $1.381-2.735 \beta$ \\
$\mathrm{Au}$ & $\mathrm{CCSD}(\mathrm{T})$ & 2.4075 & $\gamma$ & $1.641 \gamma-1.089$ & $1.089-2.641 \gamma$ \\
\hline \hline
\end{tabular}

and remains around the bond distances of free $\mathrm{CN}$ and $\mathrm{CN}^{-}$. The relativistic effects of the MCN complexes are under more comprehensive investigation.

\section{ACKNOWLEDGMENTS}

This work was supported by the Korea Research Foundation Grant funded by the Korean Government (MOEHRD) (KRF-2006-312-C00191) in which computational resources were provided by the Supercomputing Center of the Korea Institute of Science Technology Information (KISTI), a grant (06K1401-01010) from Center for Nanoscale Mechatronics and Manufacturing, one of the 21st Century Frontier Research Programs which are supported by Ministry of Science and Technology, Korea, and the CNRS through the IDRIS, Orsay (Project 051825). One of the authors (G.H.J.) would like to thank the KOFST for the support through the Brain Pool Program 2005. Another author (D.H.R.) would like to thank the Chemistry Department of the KAIST for hospitality during his stay in 2005 .

${ }^{1}$ M. L. Klein, J. D. Goddard, and D. G. Bounds, J. Chem. Phys. 75, 3909 (1981)

${ }^{2}$ P. E. S. Wormer and J. Tennyson, J. Chem. Phys. 75, 1245 (1981). R. Esser, J. Tennyson, and P. E. S. Wormer, Chem. Phys. Lett. 89, 223 (1982).

${ }^{3}$ C. J. Marsden, J. Chem. Phys. 76, 6451 (1982).

${ }^{4}$ P. R. von Schleyer, A. Sawaryn, E. A. Reed, and P. Hobza, J. Comput. Chem. 7, 666 (1986).

${ }^{5}$ J. Makarewicz and T.-K. Ha, Chem. Phys. Lett. 232, 497 (1995).

${ }^{6}$ S. Petrie, J. Phys. Chem. 100, 11581 (1996); Phys. Chem. Chem. Phys. 1, 2897 (1999).

${ }^{7}$ G. E. Leroi and W. Klemperer, J. Chem. Phys. 35, 774 (1961).

${ }^{8}$ Chemistry Webbook from the NIST website (http://nist.gov/).

${ }^{9}$ Z. K. Ismail, R. H. Hauge, and J. L. Margrave, J. Chem. Phys. 57, 5137 (1972); J. Mol. Spectrosc. 45, 304 (1973); J. Mol. Spectrosc. 54, 402 (1975).
${ }^{10}$ J. J. van Vaals, W. Leo Meerts, and A. Dymanus, Chem. Phys. 82, 385 (1983); Chem. Phys. 86, 147 (1984).

${ }^{11}$ T. Törring, J. P. Bekooy, W. Leo Meerts, J. Hoeft, E. Tiemann, and A. Dymanus, J. Chem. Phys. 73, 4875 (1980).

${ }^{12}$ L. T. Redmon, G. D. Purvis III, and R. J. Bartlett, J. Chem. Phys. 72, 986 (1980)

${ }^{13}$ V. S. Rao, A. Vijay, and A. K. Chandra, Can. J. Chem. 74, 1072 (1996).

${ }^{14}$ S. C. Farantos and J. Tennyson, J. Chem. Phys. 82, 800 (1985).

${ }^{15}$ C. J. Nelin, P. S. Bagus, and M. R. Philpott, J. Chem. Phys. 87, 2170 (1987).

${ }^{16}$ I. Garcia Cuesta, A. Sanchez de Meras, and I. Nebot-Gil, Chem. Phys. 170, 1 (1993).

${ }^{17}$ A. Veldkamp and G. Frenking, Organometallics 12, 4613 (1993).

${ }^{18}$ L. Bouslama, A. Daoudi, H. Mestdagh, C. Rolando, and M. Suard, J. Mol. Struct.: THEOCHEM 330, 187 (1995).

${ }^{19}$ A. I. Boldyrev, X. Li, and L.-S. Wang, J. Chem. Phys. 112, 3627 (2000).

${ }^{20}$ O. Dietz, V. M. Rayon, and G. Frenking, Inorg. Chem. 42, 4977 (2003).

${ }^{21}$ C. W. Bauschlicher, Jr., Surf. Sci. 154, 70 (1985).

${ }^{22}$ D. B. Grotjahn, M. A. Brewster, and L. M. Ziurys, J. Am. Chem. Soc. 124, 5895 (2002)

${ }^{23}$ A. Paul, Y. Yamaguchi, H. F. Schaefer III, and K. A. Peterson, J. Chem. Phys. 124, 034310 (2006).

${ }^{24}$ B. Bak, E. Clementi, and R. N. Kortzeborn, J. Chem. Phys. 52, 764 (1970); E. Clementi, H. Kistenmacher, and H. Popkie, ibid. 58, 2460 (1973).

${ }^{25}$ D.-K. Lee, Y. S. Lee, D. Hagebaum-Reignier, and G.-H. Jeung, Chem. Phys. 327, 406 (2006); G.-H. Jeung, Theor. Chem. Acc. 116, 450 (2006).

${ }^{26} \mathrm{~K}$. Andersson, F. Aquilante, M. Barysz et al., MOLCAs, University of Lund, 1997.

${ }^{27}$ H.-J. Werner, P. J. Knowles, R. Lindh et al., MOLCAS, Stuttgart University and Cardiff University, 2000.

${ }^{28}$ M. J. Frisch G. W. Trucks, H. B. Schlegal et al., GAussian, Gaussian, Inc., Pittsburgh, PA, 2003.

${ }^{29}$ I. S. Lim, P. Schwerdtfeger, B. Metz, and H. Stoll, J. Chem. Phys. 122, 104103 (2005).

${ }^{30}$ D. Figgen, G. Rauhut, M. Dolg, and H. Stoll, Chem. Phys. 311, 227 (2005).

${ }^{31}$ S. E. Bradforth, E. H. Kim, and D. W. Arnold, J. Chem. Phys. 98, 800 (1993).

${ }^{32}$ G.-H. Jeung, J. Am. Chem. Soc. 114, 3211 (1992); G. H. Jeung and J. Koutecký, Chem. Phys. Lett. 129, 569 (1986). 